\title{
OPTIMIZATION OF PERFORATED DOUBLELAYER ABSORBERS USING SIMULATED ANNEALING
}

\author{
Min-Chie Chiu \\ Ying-Chun Chang \\ Department of Mechanical Engineering, Tatung University. \\ Long-Jyi Yeh \\ Department of Mechanical Engineering, Tatung University. \\ Tian-Syung Lan \\ Department of Information Management, Yu Da College of Business.
}

Department of Automatic Control Engineering, Chungchou Institute of Technology., minchie.chiu@msa.hinet.net

Follow this and additional works at: https://jmstt.ntou.edu.tw/journal

Part of the Electrical and Computer Engineering Commons

\section{Recommended Citation}

Chiu, Min-Chie; Chang, Ying-Chun; Yeh, Long-Jyi; and Lan, Tian-Syung (2007) "OPTIMIZATION OF PERFORATED DOUBLELAYER ABSORBERS USING SIMULATED ANNEALING," Journal of Marine Science and Technology. Vol. 15:

Iss. 4, Article 10.

DOI: $10.51400 / 2709-6998.2052$

Available at: https://jmstt.ntou.edu.tw/journal/vol15/iss4/10

This Research Article is brought to you for free and open access by Journal of Marine Science and Technology. It has been accepted for inclusion in Journal of Marine Science and Technology by an authorized editor of Journal of Marine Science and Technology. 


\title{
OPTIMIZATION OF PERFORATED DOUBLE- LAYER ABSORBERS USING SIMULATED ANNEALING
}

\author{
Min-Chie Chiu*, Ying-Chun Chang**, Long-Jyi Yeh**, Tian-Syung Lan***
}

Key words: double-layer absorber, transfer matrix method, optimization, simulated annealing.

\section{ABSTRACT}

As noise is highly responsible for the psychological and physiological ills to workers, the noise control for enclosed manufacturing system with sound absorber becomes obligatory; besides, considering the maintenance and operation in a room, the minimal thickness of sound absorber is certainly requested, according. To meet these issues, the compromising design target, ratio of sound absorption coefficient to thickness of acoustic panel, is thus proposed and applied as a researched objective, accordingly.

In this paper, the simulated annealing (SA) is utilized in the shape optimization of the double-layer sound absorption system. The paper tackles not only the theoretical derivation in a double-layer sound absorption system, but also, the presentation of the SA searching techniques. By pre-running the optimal searches of sound absorption coefficient of a single-layer absorber at the specified frequency of $350 \mathrm{~Hz}$, the reliability in SA was verified. Before optimization, the accuracy of mathematic model on a single-layer sound absorber has been confirmed to be in good agreement by the experimental data. Thereafter, the exemplified case of double-layer absorber in seeking for the optimal objective function, ratio of sound absorption coefficient to thickness of acoustic panel, at the targeted $400 \mathrm{~Hz}$ is thus applied in the following SA optimization.

The economical and compact design of sound absorber proposed in this study surely provides a quick and optimal approach to maximize the acoustic performance at fixed total thickness and given flow resistivities of acoustic fibers by adjusting the airspace, acoustic fiber, perforated design of front plate on the perforated double-layer absorbers.

\section{NOMENCLATURE}

This paper is constructed on the basis of the following notations:

Paper Submitted 08/28/06, Accepted 01/10/07. Author for Correspondence: Min-Chie Chiu.E-mail: minchie.chiu@msa.hinet.net

*Department of Automatic Control Engineering, Chungchou Institute of Technology.

**Department of Mechanical Engineering, Tatung University.

***Department of Information Management, Yu Da College of Business. $c_{o}:$ sound speed $\left(\mathrm{m} \mathrm{s}^{-1}\right)$

$d_{i}$ : diameter of perforated hole on the $i$-th front plate (m)

Do: thickness of absorber (m)

$D f_{i}$ : thickness of the $i$-th acoustic fiber (m)

$f$ : cyclic frequency

$j: \sqrt{-1}$.

$K_{\text {fiberi }}$ : complex propagation constant of the $i$-th acoustic fiber

$K_{p}$ : complex propagation constant of the perforated front plate

$K_{1 A}$ : real part of complex $K_{\text {fiber } 1}$

$K_{2 A}$ : imaginary part of complex $K_{\text {fiber } 1}$

$L_{i}$ : air depth of the $i$-layer resonator $(\mathrm{m})$

$m_{i}$ : surface density of the $i$-th perforated front plate per $1 \mathrm{~m}^{2}\left(\mathrm{~kg} \mathrm{~m}^{-2}\right)$

$N_{i}$ : hole's number on the $i$-th perforated front plate per $1 \mathrm{~m}^{2}$

$O B J_{1}$ : objective function $\left(\alpha /\left(D f_{1}+D f_{2}\right)\right)$

$O B J_{2}:$ objective function $(\alpha)$

$p_{i} \%$ : perforated ratio of the $i$-th perforated front plate $(\%)$

$p_{i}$ : acoustic pressure at $i(\mathrm{~Pa})$

$q_{i}$ : thickness of the $i$-th perforated front plate $(\mathrm{m})$

$R_{a}$ : acoustic flow resistivity of the first acoustic fiber $\left(\mathrm{MKS}\right.$ rayls $\mathrm{m}^{-1}$ )

$R_{b}$ : acoustic flow resistivity of the second acoustic fiber (MKS rayls $\mathrm{m}^{-1}$ )

$R_{f i b e r(i)}$ : real part of complex $Z_{\text {fiber }(i)}$

$u_{i}$ : acoustic particle velocity at $i\left(\mathrm{~kg} \mathrm{~s}^{-1}\right)$

$\omega$ : angular frequency $\left(\mathrm{rad} \mathrm{s}^{-1}\right)$

$Z_{i}$ : specific normal impedance at $i$.

$Z_{\text {fiber }(i)}$ : characteristic impedance of the ith acoustic fiber

$Z_{p i}$ : characteristic impedance of the ith perforated front plate

$X_{f i b e r(i)}$ : imaginary part of complex $Z_{\text {fiber }(i)}$

$\alpha$ : sound absorption coefficient of absorber

$\rho_{\mathrm{o}}$ : air density $\left(\mathrm{kg} \mathrm{m}^{-3}\right)$

iter $_{\text {max }}$ : maximum iteration in SA

$T_{o}$ : initial temperature

$k k$ : cooling rate in SA 


\section{INTRODUCTION}

For the purposes of people's health and sufficient space of maintenance and operation inside the constrained machine room, the optimal shape to maximize the performance of the absorber at the minimal volume of absorbers is thus compulsory. The research of unconstrained multi-layer sound absorber has been discussed by Lee et al. [8]; however, the thickness of sound absorber is unlimited. A numerical assessment with gradient method and graphic analysis of a fixed thickness sound absorption on perforated single-layer absorbers was deduced and discussed in the previous work [3]. To improve the sound absorption and decrease the total thickness of sound absorber, a numerical assessment of a variable thickness double-layer absorber is then proposed in the studies. Besides, to efficiently explore the optimal design data, the simulated annealing (SA) [7, 9], a stochastic relaxation technique based on the analogy of the physical process of annealing metal, is applied. Besides, a matrix transfer conception for sound absorption [4] is utilized in the derivation of the normal sound absorption coefficient. In addition, the half-experienced formula of specific normal impedance by Delany and Bazley [5] as well as by Ingard and Bolt [6] are both included into the model derivation simultaneously.

\section{THEORETICAL BACKGROUND}

A matrix transfer method is adopted to formulate a mathematical model for the resonator of which is comprised of a panel, perforated with small holes backed by an air space, and wool. The acoustic impedance of the multi-layer panel on the perforated front plate of the absorbers is determined from the results of the observations at the bottom wall of the infinity of impedance [1].

For a plane wave propagating perpendicularly through a partitioned (with $b$ in length and $h$ in width) and uniform section filled with quiescent medium (symbolized by " $\mathrm{m}$ ") which is homogeneous and isotropic shown in Figure 1, the general matrix form between point 1 and point 2 is expressed as [3]

$$
\left(\begin{array}{l}
p_{2} \\
u_{2}
\end{array}\right)=\left[\begin{array}{cc}
\cos \left(k_{m} L\right) & j Z_{m} \sin \left(k_{m} L\right) \\
j \frac{1}{Z_{m}} \sin \left(k_{m} L\right) & \cos \left(k_{m} L\right)
\end{array}\right]\left(\begin{array}{l}
p_{1} \\
u_{1}
\end{array}\right)
$$

On the basis of plane wave assumption, the formula will be valid at

$$
f<\frac{c_{o}}{2 h}
$$

In dealing with the sound absorption mechanism of a double-layer perforated absorber shown Figure 2, the structure of a partitioned double-layer sound absorber include (1) $L_{1}$ thickness of the air space; (2)D $D f_{1}$ thickness of absorbing wool layer; (3) $q_{1}$ thickness of the perforated front plate; (4) $L_{2}$ thickness of the air space; (5) $D f_{2}$ thickness of absorbing wool layer; and (6) $q_{2}$ thickness of the perforated front plate.

By using Eq.(1), the transfer matrix of acoustic pressure $p$ and acoustic particle velocity $u$ between points 0 and 1 can be expressed as [4]

$$
\left[\begin{array}{l}
p_{1} \\
u_{1}
\end{array}\right]=\left[\begin{array}{cc}
\cos \left(\omega L_{1} / c_{o}\right) & j \rho_{o} c_{o} \sin \left(\omega L_{1} / c_{o}\right) \\
j \frac{\sin \left(\omega L_{1} / c_{o}\right)}{\rho_{o} c_{o}} & \cos \left(\omega L_{1} / c_{o}\right)
\end{array}\right]\left[\begin{array}{l}
p_{o} \\
u_{o}
\end{array}\right]
$$

Where $p_{1}$ is the sound pressure at the surface of the air layer, $u_{1}$ is the acoustic particle velocity at the surface of the air layer, $p_{0}$ is the acoustic pressure at the wall, $u_{0}$ is the acoustic particle velocity at the wall. The normal impedance $Z_{\text {air }}$ at the air layer is simplified in the following expression:

$$
Z_{1}=Z_{\text {air }}=-j \rho_{o} c_{o} \cot \left(\frac{\omega L_{1}}{c_{o}}\right)
$$

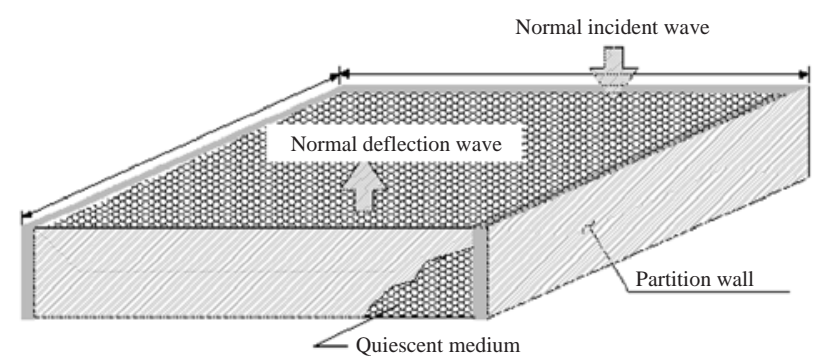

Fig. 1. Plane wave propagating through a partitioned porous material.

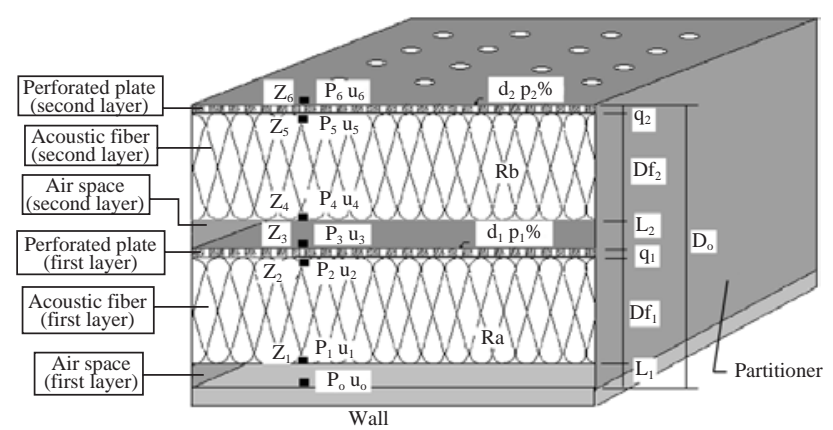

Fig. 2. The sound absorption mechanism of a double-layer perforated sound absorber. 
The transfer matrix expresses the relationship of acoustic pressure $p$ and acoustic particle velocity $u$ between points 1 and 2

$$
\left[\begin{array}{l}
p_{2} \\
u_{2}
\end{array}\right]=\left[\begin{array}{cc}
\cos \left[K_{\text {fiber } 1}\left(D f_{1}\right)\right] & j Z_{\text {fiber } 1} \sin \left[K_{\text {fiber } 1}\left(D f_{1}\right)\right] \\
j \frac{\sin \left[K_{\text {fiber } 1}\left(D f_{1}\right)\right]}{Z_{\text {fiber } 1}} & \cos \left[K_{\text {fiber } 1}\left(D f_{1}\right)\right]
\end{array}\right]\left[\begin{array}{l}
p_{1} \\
u_{1}
\end{array}\right]
$$

Substituting Eq. (4) into Eq. (5), the normal impedance $Z_{2}$ at the surface of the wool layer is derived and expressed in the matrix form:

$Z_{2}=\frac{Z_{1} \cos \left[K_{\text {fiber } 1}\left(D f_{1}\right)\right]+j\left(R_{\text {fiber } 1}+j X_{\text {fiber } 1}\right) \sin \left[K_{\text {fiber } 1}\left(D f_{1}\right)\right]}{j Z_{1} \frac{\sin \left[K_{\text {fiber } 1}\left(D f_{1}\right)\right]}{R_{\text {fiber } 1}+j X_{\text {fiber } 1}}+\cos \left[K_{\text {fiber } 1}\left(D f_{1}\right)\right]}$

By adopting the formula of characteristic impedance and wave number, which is applied in fibrous material, and deriving the equation by Delany and Bazley [5], it has

$$
\begin{aligned}
& K_{1 A}=\left\{\left[\frac{\omega\left(D f_{1}\right)}{c_{o}}\right]\left[1+0.0978\left(\frac{\rho_{o} f}{R_{a}}\right)^{-0.700}\right]\right\} ; \\
& K_{2 A}=\left\{\left[\frac{\omega\left(D f_{1}\right)}{c_{o}}\right]\left[-0.189\left(\frac{\rho_{o} f}{R_{a}}\right)^{-0.595}\right]\right\} \\
& R_{f i b e r 1}=\rho_{o} c_{o}\left(1+0.0571\left(\frac{\rho_{o} f}{R_{a}}\right)^{-0.754}\right) ; \\
& X_{\text {fiber } 1}=\rho_{o} c_{o}\left(-0.087\left(\frac{\rho_{o} f}{R_{a}}\right)^{-0.732}\right)
\end{aligned}
$$

Where $K_{\text {fiber } 1}=K_{1 A}+j K_{2 A} ; 1000 \leq R_{a} \leq 50000$

The transfer matrix expresses the relationship of acoustic pressure $p$ and acoustic particle velocity $u$ between points 2 and 3

$$
\left[\begin{array}{l}
p_{3} \\
u_{3}
\end{array}\right]=\left[\begin{array}{cc}
\cos \left(K_{p 1} q_{1}\right) & j Z_{p 1} \sin \left(K_{p 1} q_{1}\right) \\
j \frac{\sin \left(K_{p 1} q_{1}\right)}{Z_{P 1}} & \cos \left(K_{p 1} q_{1}\right)
\end{array}\right]\left[\begin{array}{l}
p_{2} \\
u_{2}
\end{array}\right]
$$

By adopting the formula of specific normal impedance and wave number of the perforated plate, derived by Ingard and Bolt [6], the normal impedance $Z_{3}$ at the surface of the perforated front plate is simplified to:

$$
Z_{3}=Z_{p 1} \frac{Z_{2}+j Z_{p 1} \tan \left(K_{p 1} q_{1}\right)}{Z_{p 1}+j Z_{2} \tan \left(K_{p 1} q_{1}\right)}
$$

Where

$$
\begin{aligned}
& Z_{p 1}=j 32 \pi f M_{h 1} /\left(\left[1+\frac{16 M_{h 1}}{m_{1} N_{1} \pi^{2} d_{1}^{4}}\right]\left[N_{1} \pi^{2} d_{1}^{4}\right]\right) \\
& M_{h 1}=\rho_{o}\left[\frac{\pi d_{1}^{2} q_{1}}{4}+2 \frac{d_{1}^{3}}{3}\right]
\end{aligned}
$$

Similarly, the acoustical transfer matrices for the second (upper) layer absorber between points 3 and 4, 4 and 5 and 5 and 6 are:

$$
\left[\begin{array}{l}
p_{4} \\
u_{4}
\end{array}\right]=\left[\begin{array}{cc}
\cos \left(\omega L_{2} / c_{o}\right) & j \rho_{o} c_{o} \sin \left(\omega L_{2} / c_{o}\right) \\
j \frac{\sin \left(\omega L_{2} / c_{o}\right)}{\rho_{o} c_{o}} & \cos \left(\omega L_{2} / c_{o}\right)
\end{array}\right]\left[\begin{array}{l}
p_{3} \\
u_{3}
\end{array}\right]
$$

$\left[\begin{array}{l}p_{5} \\ u_{5}\end{array}\right]=\left[\begin{array}{cc}\cos \left[K_{f i b e r 2}\left(D f_{2}\right)\right] & j\left(R_{f i b e r 2}+j X_{\text {fiber } 2}\right) \cdot \sin \left[K_{\text {fiber } 2}\left(D f_{2}\right)\right] \\ j \frac{\sin \left[K_{\text {fiber } 2}\left(D f_{2}\right)\right]}{R_{\text {fiber } 2}+j X_{f i b e r 2}} & \cos \left[K_{f i b e r} 2\left(D f_{2}\right)\right.\end{array}\right]\left[\begin{array}{l}p_{4} \\ u_{4}\end{array}\right]$

$$
\left[\begin{array}{l}
p_{6} \\
u_{6}
\end{array}\right]=\left[\begin{array}{cc}
\cos \left(K_{p 2} q_{2}\right) & j Z_{p 2} \sin \left(K_{p 2} q_{2}\right) \\
j \frac{\sin \left(K_{p 2} q_{2}\right)}{Z_{p 2}} & \cos \left(K_{p 2} q_{2}\right)
\end{array}\right]\left[\begin{array}{l}
p_{5} \\
u_{5}
\end{array}\right]
$$

Developing and rearranging Eqs. (10) (12), the normal impedances of $Z_{4}, Z_{5}$ and $Z_{6}$ can be expressed as:

$$
Z_{4}=Z_{\text {air }} \frac{Z_{3}+j Z_{\text {air }} \tan \left(\omega L_{2} / c_{o}\right)}{j \tan \left(\omega L_{2} / c_{o}\right) Z_{3}+Z_{\text {air }}}
$$

$Z_{5}$

$$
=\frac{Z_{4} \cos \left[K_{\text {fiber } 2}\left(D f_{2}\right)\right]+j\left(R_{\text {fiber } 2}+j X_{\text {fiber } 2}\right) \sin \left[K_{\text {fiber } 2}\left(D f_{2}\right)\right]}{j Z_{4} \frac{\sin \left[K_{\text {fiber } 2} 2\left(D f_{2}\right)\right]}{R_{\text {fiber } 2}+j X_{\text {fiber } 2}}+\cos \left[K_{\text {fiber } 2}\left(D f_{2}\right)\right]}
$$

$$
Z_{6}=Z_{p 2} \frac{Z_{5}+j Z_{p 2} \tan \left(K_{p 2} q_{2}\right)}{Z_{p 2}+j Z_{5} \tan \left(K_{p 2} q_{2}\right)}
$$


Where

$$
\begin{aligned}
& K_{\text {fiber } 2}=K_{1 B}+j K_{2 B} ; \\
& K_{1 B}=\left\{\left[\frac{\omega\left(D f_{2}\right)}{c_{o}}\right]\left[1+0.0978\left(\frac{\rho_{o} f}{R_{b}}\right)^{-0.700}\right]\right\} ; \\
& K_{2 A}=\left\{\left[\frac{\omega\left(D f_{2}\right)}{c_{o}}\right]\left[-0.189\left(\frac{\rho_{o} f}{R_{b}}\right)^{-0.595}\right]\right\} ; \\
& R_{\text {fiber } 2}=\rho_{o} c_{o}\left(1+0.0571\left(\frac{\rho_{o} f}{R_{b}}\right)^{-0.754}\right) ; \\
& X_{\text {fiber } 2}=\rho_{o} c_{o}\left(-0.087\left(\frac{\rho_{o} f}{R_{b}}\right)^{-0.732} ;\right. \\
& 1000 \leq R_{b} \leq 50000 ; \\
& Z_{p 2}=j 32 \pi f M_{h 2} /\left(\left[1+\frac{16 M_{h 2}}{m_{2} N_{2} \pi^{2} d_{2}^{4}}\right]\left[N_{2} \pi^{2} d_{2}^{4}\right]\right) ; \\
& M_{h 2}=\rho_{o}\left[\frac{\pi d_{2}^{2} q_{2}}{4}+2 \frac{d_{2}^{3}}{3}\right]
\end{aligned}
$$

For normal incidence, the sound absorption coefficient [1] is shown as:

$$
\begin{gathered}
\alpha\left(f, m_{1}, q_{1}, p_{1} \%, d_{1}, D f_{1}, L_{1}, R_{a}, m_{2}, q_{2}, p_{2} \%, d_{2},\right. \\
\left.D f_{2}, L_{2}, R_{b}\right)=1-\left|\frac{Z_{6}-\rho_{o} c_{o}}{Z_{6}+\rho_{o} c_{o}}\right|^{2}
\end{gathered}
$$

In finding an economical design of double-layer sound absorbers with smaller thickness and higher sound absorption, the objective function is defined as

$$
\begin{aligned}
O B J_{1}= & \alpha\left(f, m_{1}, q_{1}, p_{1} \%, d_{1}, D f_{1}, L_{1}, R_{a}, m_{2}, q_{2},\right. \\
& \left.p_{2} \%, d_{2}, D f_{2}, L_{2}, R_{b}\right) /\left(D f_{1}+D f_{2}\right)
\end{aligned}
$$

\section{MODEL CHECK}

\section{Mathematic model}

To verify the accuracy of a fundamental mathematical model in above section, a single-layer sound absorber shown in Figure 3 is exemplified. Its mathematic form of the normal sound absorption coefficient is

$$
\begin{aligned}
& \alpha\left(f, m_{1}, q_{1}, p_{1} \%, d_{1}, D f_{1}, L_{1}, R_{a}\right) \\
& \quad=1-\left|\frac{Z_{3}-\rho_{o} c_{o}}{Z_{3}+\rho_{o} c_{o}}\right|^{2}
\end{aligned}
$$

An experimental equipment for measuring the normal sound absorption coefficient is designed and depicted in Figure 4. As indicated in Figure 4, the acoustic impedance tube emits the normal incident plane wave and detects the standing wave with a movable microphone.

One sample of a single-layer sound absorber is simulated and tested wherein $R_{1}$ is a flow resistivity of absorbing fiber [12]. The accuracy comparisons between the theoretical and the experimental results are illustrated in Figure 5. The results in Figure 5 show that they are in agreements.

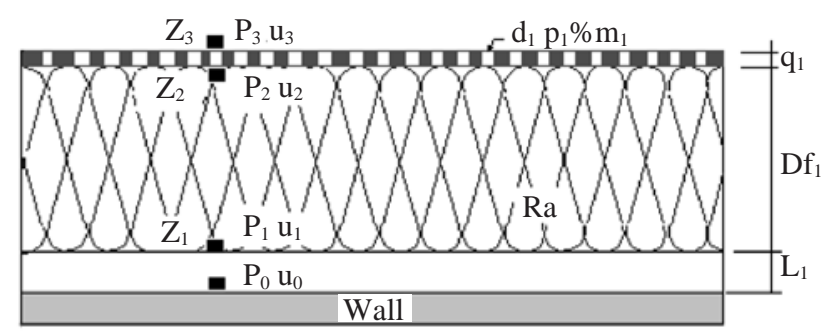

Fig. 3. A single-layer sound absorber with variables of $p \%, d, D f, L$ and $R$.

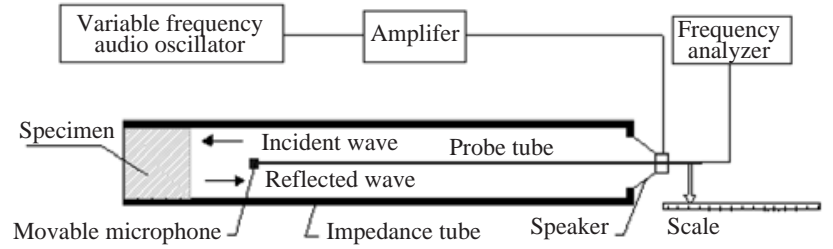

Fig. 4. The experiment of normal sound absorption coefficient by an impedance tube.

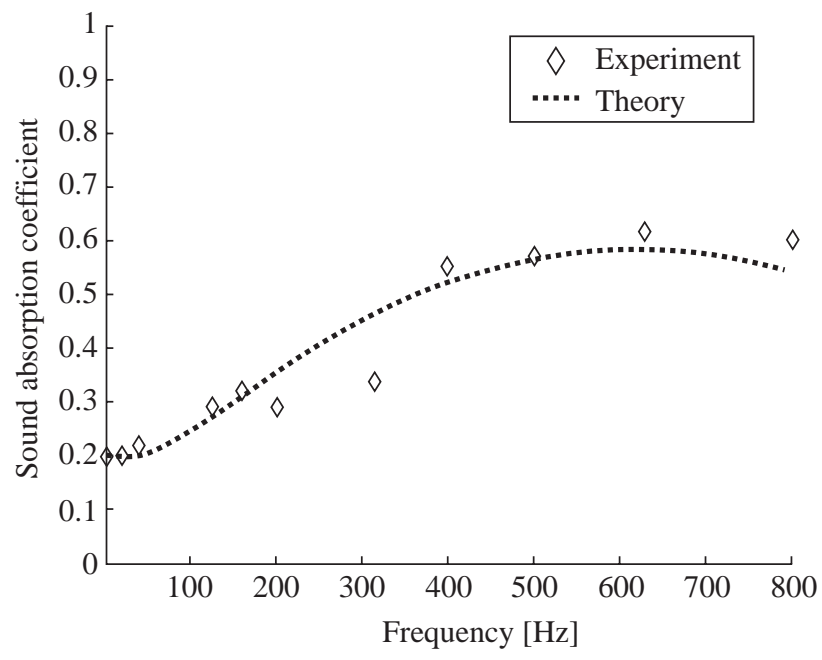

Fig. 5. Accuracy check for theoretical model of a single-layer sound absorber $\left[L_{1}=0.05(\mathrm{~m}), D_{f 1}=0.046(\mathrm{~m}), p_{1} \%=19.4(\%), d_{1}=0.003\right.$ $\left.(\mathrm{m}), R_{1}=8000(\mathrm{rayls} / \mathrm{m}), m_{1}=2\left(\mathrm{~kg} / \mathrm{m}^{2}\right), q_{1}=0.001(\mathrm{~m})\right]$. 


\section{Reliability of the simulated annealing}

To verify the reliability of SA optimization, a single-layer sound absorber with variables of $[p \%, d$, $D f, L$ and $R$ ] shown in Figure 3 is introduced for pre-run purpose.

The exemplified objective function of the sound absorption coefficient for a single-layer sound absorber is

$$
\begin{aligned}
O B J_{2} & =\alpha\left(f, m_{1}, q_{1}, p_{1} \%, d_{1}, D f_{1}, L_{1}, R_{a}\right) \\
& =1-\left|\frac{Z_{3}-\rho_{o} c_{o}}{Z_{3}+\rho_{o} c_{o}}\right|^{2}
\end{aligned}
$$

The targeted frequency is set at $350 \mathrm{~Hz}$ for the SA optimization. By using SA optimization, the resultant sound absorption coefficient with respect to frequency domain is plotted in Figure 6. As indicated in Figure 6 that the sound absorption coefficient is precisely maximized at the desired frequency of $350 \mathrm{~Hz}$. Therefore, the reliability of SA optimization is acceptable.

Consequently, the proposed fundamental mathematical model and SA are reliable. Thereafter, the advanced exploration of double-layer sound absorbers in conjugated with SA is developed and applied in the following sections:

\section{SIMULATED ANNEALING}

Simulated annealing (SA) algorithm, a local search process, simulates the annealing process of metal. In the physical system, annealing is the process of melting

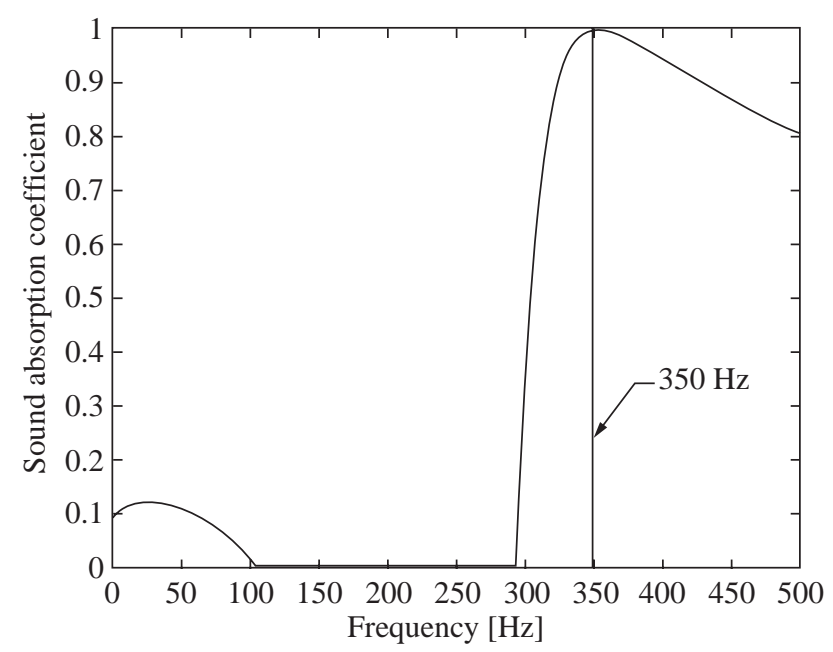

Fig. 6. Sound absorption coefficient of a single-layer absorber with respect to frequency $\left[p_{1} \%=47.2(\%), d_{1}=0.012(\mathrm{~m}), D_{f 1}=0.118\right.$ $(\mathrm{m}), L_{1}=0.088(\mathrm{~m}), R_{1}=46069(\mathrm{rayls} / \mathrm{m}), m_{1}=2\left(\mathrm{~kg} / \mathrm{m}^{2}\right), q_{1}=$ $0.0006(\mathrm{~m})]$. a metal and cooling it until the material is crystallized. The slow cooling (annealing) allows the particles to move towards the minimal energy state. In this state, the particles have a more uniform crystalline structure. However, the fast cooling rate (quenching) results in the higher energy condition with large internal energy stored inside the imperfect lattice. The basic concept behind the SA was first introduced by Metropolis et al. [9] and developed by Kirkpatrick et al. [7]. The purpose of the SA is to avoid stacking local optimal solutions during optimization.

The scheme of the SA is a variation of the hillclimbing algorithm. All downhill movements for improvement are accepted for the decrement of the system energy. Simultaneously, the SA also allows movement resulting in worse solutions (uphill moves) than the current solution in order to escape from the local optimum. At higher temperatures, the uphill movement changes well. However, changes occur when going uphill is decreased and the temperature lowers.

The flow diagram regarding SA optimization is described and shown in Figure 7. As indicated in Figure 7 , the initial temperature $\left(T_{o}\right)$, maximal iteration number $\left(\right.$ iter $\left._{\max }\right)$ and cooling rate $(k k)$ have been firstly preset in program; the algorithm starts by generating a random initial solution $(X n)$. To simulate the evolution of the $\mathrm{SA}$ algorithm, a new random solution $\left(X n^{\prime}\right)$ is chosen from the neighborhood of the current solution. If the change $(\Delta F)$ in energy (or objective function) is negative, the new solution $\left(X n^{\prime}\right)$ is accepted as the new current solution $(X n)$. Otherwise, the transition property $(p b(T))$ of accepting the increase is computed by evaluating the Boltzmann's factor $(p b(T)=\exp (\triangle F / C T))$ in which the $\Delta F, C$ and $T$ are the difference of the objective function , Boltzmann constant and current temperature respectively. Each successful replacement of the new current solution leads to the decrement of the current temperatur $\left(T_{\text {new }}\right)$ by $T_{\text {new }}=k k^{*} T_{\text {old }}$, wherein $k k$ is a cooling rate in this annealing process. The iteration check of iter $_{\max }$ has also been ensured in advance before next seeking of new solution being repeated again. The process is recurring until the predetermined number $\left(\right.$ iter $\left._{\max }\right)$ of the outer loop is reached. To achieve an initial transition probability of 0.5 , the initial temperature $\left(T_{o}\right)$ will be chosen at 0.2 [10]. If the probability is greater than a random number in the interval of $[0,1]$, the new solution is then accepted. If not, it is rejected. The algorithm iterates the perturbation of the current solution and the measurement of the change in objective function.

\section{CASE STUDY}

The noise control of a machine fan room shown in 


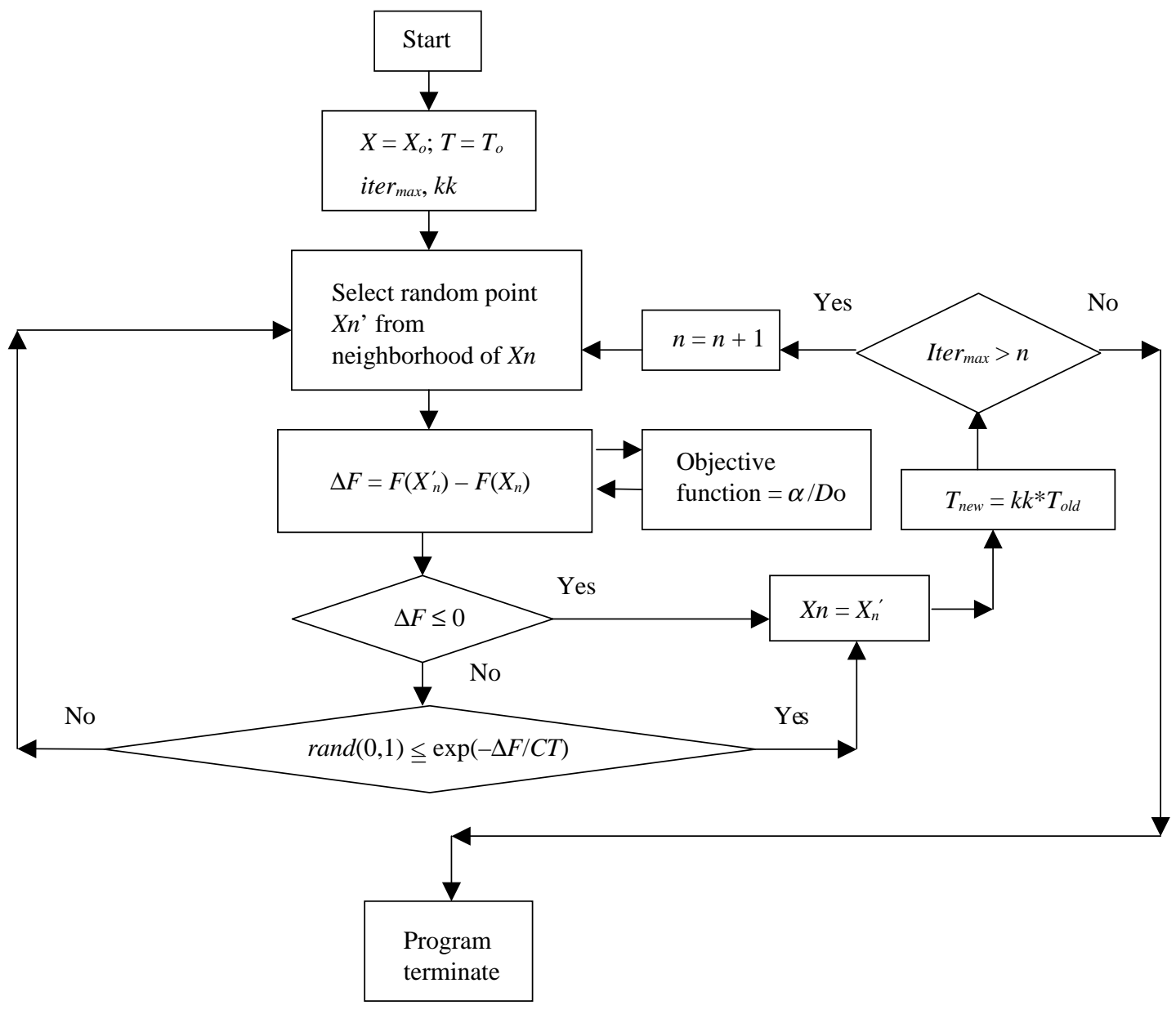

Fig. 7. Flow diagram of SA optimization.

Figure 8 is introduced in the case study.

Due to the periodic disturbance of the in-flow happening within the fan, the phenomenon of sireneffect occurs. A pure tone, $f$ of $400 \mathrm{~Hz}$, is identified and given as [11]

$$
f=N b^{*} n
$$

Where the $N b$ is the number of blades and $n$ is the rotational speed. These components and its harmonics can be readily identified in the noise spectrum of the machine. To eliminate the pure tone noise in the fan machine room, the double-layer sound absorber attached onto the wall is used. Considering both of the cost effect and the maximal available space of operation due to fan's maintenance, a compromising objective function of $\alpha /\left(D f_{1}+D f_{2}\right)$ is proposed and optimized by simulated annealing wherein the total thickness $\left(D f_{1}\right.$ $+D f_{2}$ ) of two layers of fibers are fixed to be 0.1 meter; besides, the flow resistiivity of two fibers are preselected as 6300 (rayls $/ \mathrm{m}$ ) and 40000 (rayls $/ \mathrm{m}$ )

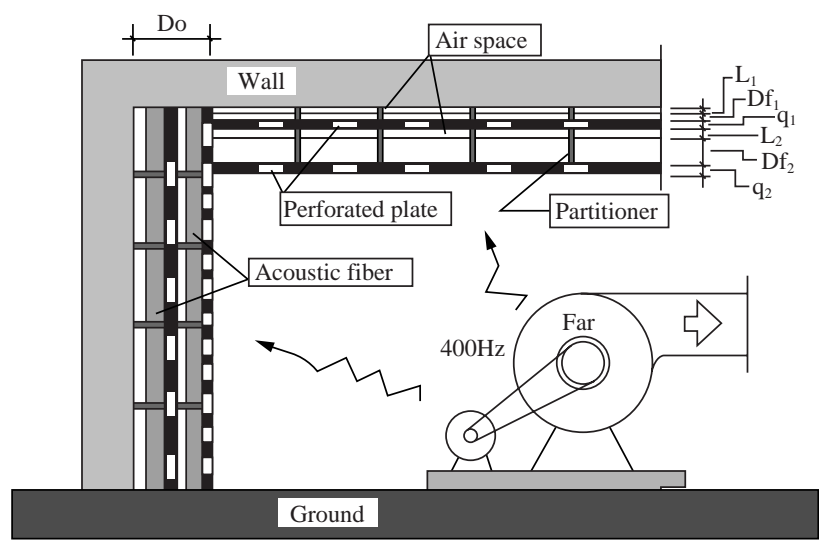

Fig. 8. Noise control of a machine fan room.

individually. Moreover, the partition design of the absorber is 0.2 meter in $b$ and $h$ concurrently. By adopting Eq.(2), the cutoff frequency $\left(f_{c}\right)$ is

$$
f_{c}=C o / 2 h=340 /(2 * 0.2)=850(\mathrm{~Hz})
$$


For the purposes of lightness in metal, a series of assumptions for the constrained conditions in the design are illustrated as:

$f_{\text {target }}=400(\mathrm{~Hz}) ; q_{1}=q_{2}=0.006(\mathrm{~m}) ; m_{1}=m_{2}=2\left(\mathrm{~kg} / \mathrm{m}^{2}\right) ;$ $5.0(\%) \leq p_{1} \leq 50.0(\%) ; 0.003(\mathrm{~m}) \leq d_{1} \leq 0.015(\mathrm{~m})$; $0.01(\mathrm{~m}) \leq L_{1} \leq 0.1(\mathrm{~m}) ; 5.0(\%) \leq p_{2} \leq 50.0(\%)$; $0.003(\mathrm{~m}) \leq d_{2} \leq 0.015(\mathrm{~m}) ; 0.01(\mathrm{~m}) \leq L_{2} \leq 0.1(\mathrm{~m})$; $R_{a}=6300($ rayls $/ \mathrm{m}) ; R_{b}=40000.0($ rayls $/ \mathrm{m})$; $0.02(\mathrm{~m}) \leq D f_{1} \leq 0.0 .8(\mathrm{~m})$

The corresponding $O B J_{1}$ is simplified as

$$
\begin{aligned}
O B J_{1}= & \alpha\left(f_{\text {target }}, p_{1} \%, d_{1}, D f_{1}, L_{1}, p_{2} \%, d_{2}, D f_{2}, L_{2}\right) \\
& /\left(D f_{1}+D f_{2}\right)
\end{aligned}
$$

Where

$$
D f_{2}=0.1-D f_{1}(\mathrm{~m})
$$

\section{RESULTS AND DISCUSSION}

\section{Results}

The accuracy of SA optimization depends on the cooling rate $(k k)$ and the number of iteration $\left(\right.$ iter $\left._{\text {max }}\right)$ [2]. To explore the effect of the cooling rate and the number of iteration, an investigation of SA parameters, including the cooling rate and the iteration, is then carried out as follows:

To achieve a better approach in SA, five kinds of cooling rates (varying from 0.9, 0.93, 0.96, 0.99 and 0.999 ) are tested at the maximal iteration number $\left(\right.$ iter $\left._{\text {max }}\right)$ of 5000 and the initial temperature $\left(T_{o}\right)$ of 0.2 . The results are summarized in Table 1.

In addition, the annealing response curves (with respect to five kinds of cooling rates) are plotted in Figure 9. As indicated in Table 1 and Figure 9, the best result occurred at the cooling rate of 0.93 . Consequently, the objective function of $\alpha /\left(D f_{1}+D f_{2}\right)$ (with respect to frequency in the five design cases) are shown and plotted in Figure 10.

Obviously, the best $\alpha /\left(D f_{1}+D f_{2}\right)$ at the desired frequency of $400 \mathrm{~Hz}$ is found at the cooling rate of 0.93 . In the five cases, the calculations of SA optimization (run in IBM PC - Pentium IV) are 0.22 minute around.

To achieve a better approach in SA, three kinds of maximal iteration $(500,5000$ and 50000) are tested at the cooling rate of 0.93 . The results are summarized in Table 2. As indicated in Table 2, the best result occurred at the higher iteration number of 50000 .

Consequently, the acoustic performance of $\alpha /\left(D f_{1}\right.$ $+D f_{2}$ ) (with respect to frequency in three design cases) is shown and plotted in Figure 11. Obviously, the best value of $\alpha /\left(D f_{1}+D f_{2}\right)$ at $400 \mathrm{~Hz}$ is found at the iteration number of 50000. Whereas, the longer time of 12.03 minutes is required compared to other cases.

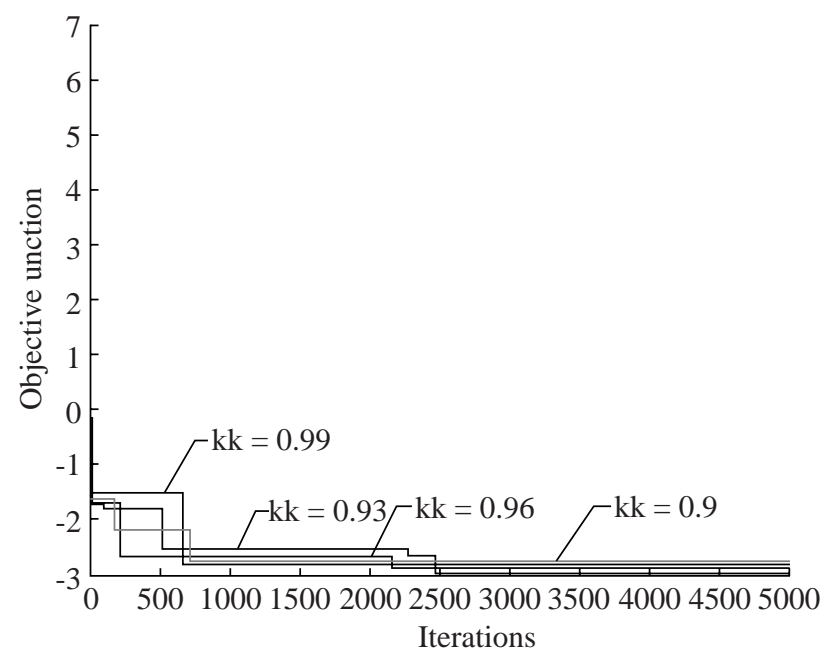

Fig. 9. Annealing response curves with respect to five kinds of cooling

\begin{tabular}{|c|c|c|c|c|c|c|c|c|c|c|c|c|c|}
\hline \multicolumn{2}{|c|}{$\begin{array}{l}\text { SA Control } \\
\text { parameters }\end{array}$} & \multicolumn{11}{|c|}{ Results } & \multirow{2}{*}{$\begin{array}{c}\begin{array}{c}\text { Elapse } \\
\text { time }\end{array} \\
\mathrm{t}(\mathrm{min})\end{array}$} \\
\hline iter $_{\text {max }}$ & $k k$ & $p_{1} \%$ & $d_{1}(\mathrm{~m})$ & $\begin{array}{l}D f_{1} \\
(\mathrm{~m})\end{array}$ & $L_{1}(\mathrm{~m})$ & $p_{2} \%$ & $d_{2}(\mathrm{~m})$ & $\begin{array}{l}D f_{2} \\
(\mathrm{~m})\end{array}$ & $L_{2}(\mathrm{~m})$ & $\begin{array}{c}\alpha / \\
\left(D f_{1}+D f_{2}\right)\end{array}$ & $\alpha$ & $D f_{1}+D f_{2}$ & \\
\hline 5000 & 0.9 & 6.0 & 0.005 & 0.079 & 0.097 & 44.8 & 0.003 & 0.021 & 0.073 & 2.87 & 0.2871 & 0.1 & 0.22 \\
\hline 5000 & $\underline{0.93}$ & 32.8 & 0.005 & 0.079 & 0.054 & 46.5 & 0.003 & 0.021 & 0.060 & 2.94 & 0.2944 & 0.1 & 0.21 \\
\hline 5000 & 0.96 & 28.4 & 0.008 & 0.079 & 0.013 & 44.9 & 0.003 & 0.021 & 0.057 & 2.92 & 0.2928 & 0.1 & 0.22 \\
\hline 5000 & 0.99 & 47.8 & 0.009 & 0.079 & 0.051 & 49.7 & 0.003 & 0.021 & 0.094 & 2.91 & 0.2917 & 0.1 & 0.22 \\
\hline 5000 & 0.999 & 44.9 & 0.009 & 0.079 & 0.034 & 47.7 & 0.004 & 0.021 & 0.062 & 2.58 & 0.2798 & 0.1 & 0.23 \\
\hline
\end{tabular}
rate.

Table 1. Comparison of results for various cooling rates

Note: $D f_{1}+D f_{2}=0.1(\mathrm{~m}) ; \mathrm{m} 1=\mathrm{m} 2=2\left(\mathrm{~kg} / \mathrm{m}^{2}\right) ; q_{1}=q_{2}=0.0006(\mathrm{~m}) ; R_{a}=6300 \mathrm{rayl} / \mathrm{m} ; R_{b}=40000 \mathrm{rayl} / \mathrm{m}$. 


\section{Discussion}

As indicated in Tables 1 and 2, the SA parameters of $k k$ and iter $_{\max }$ play the essential role during optimal process. By using $k k$ of 0.93 and iter $_{\max }$ of 50000 iterations, the best design data set of $\left(O B J_{1}=3.06\right)$ is searched as

$\left(p_{1} \%, d_{1}, D f_{1}, L_{1}, p_{2} \%, d_{2}, D f_{2}, L_{2}\right)=(38.1 \%$, $0.005 \mathrm{~m}, 0.079 \mathrm{~m}, 0.014 \mathrm{~m}, 48.5 \%, 0.003 \mathrm{~m}, 0.021 \mathrm{~m}$, $0.053 \mathrm{~m})$

The related sound absorption coefficient at the fixed total thickness $\left(D f_{1}+D f_{2}\right)$ of the sound absorber is 0.3069

Due to the selected (constrained) flow resistivity of $R_{a}$ and $R_{b}$ used in case studies, the $O B J_{1}$ values at the desired frequency of $400 \mathrm{~Hz}$ are therefore limited and unable to reach to the peak point of performance curve in Figures 10 and 11. In case of the unconstrained flow resistivity of $R_{a}$ and $R_{b}$, the optimization has been

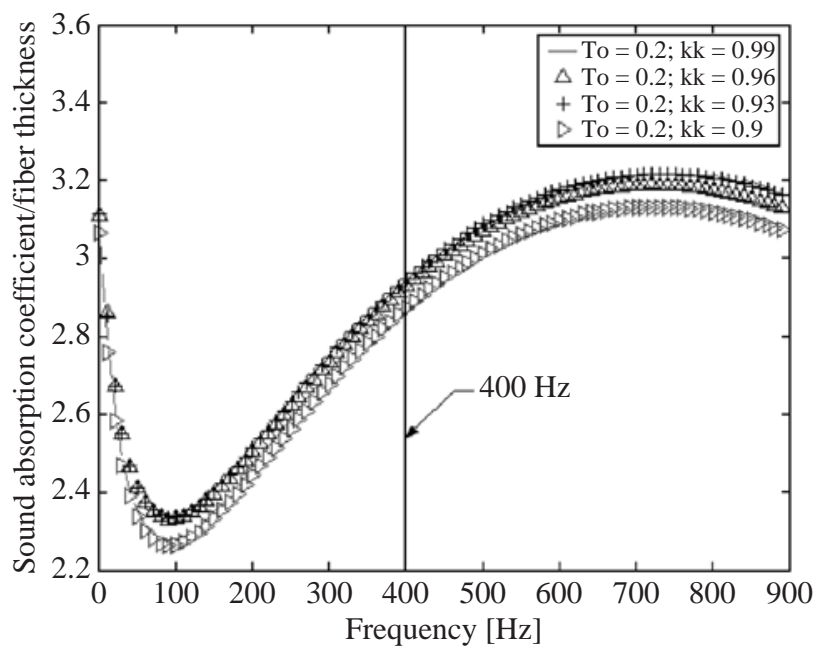

Fig. 10. Objective function of $\alpha /\left(D f_{1}+D f_{2}\right)$ with respect to frequency for various cooling rates [constraint condition: $D f_{1}+D f_{2}=0.1$ $(\mathrm{m}) ; \mathrm{m} 1=\mathrm{m} 2=2\left(\mathrm{~kg} / \mathrm{m}^{2}\right) ; q_{1}=q_{2}=0.0006(\mathrm{~m}) ; R_{a}=6300 \mathrm{rayl} / \mathrm{m} ;$ $\left.R_{\mathrm{b}}=40000 \mathrm{rayl} / \mathrm{m}\right]$ further processed; and the related performance curve at optimal design data shown in Table 3 is plotted in Figure 12. Obviously, the $O B J_{1}$ value at the targeted frequency of $400 \mathrm{~Hz}$ can be more closed to the peak point of the performance curve.

\section{CONCLUSIONS}

The maximal design objective of $\alpha /\left(D f_{1}+D f_{2}\right)$ is absolutely important and essential for a highly reverberant machine room in which the reservation spaces of maintenance and operation is extremely requested. For the economic purpose, the total thickness $\left(D f_{1}+D f_{2}\right)$ of absorbing fibers are limited to 0.1 meter. In addition, it is shown that the SA can be used in the optimization of a double-layer sound absorption system efficiently. Since using this method does not require the usual mathematical conditions of strict continuity, differentiability, convexity, and other properties, the SA be-

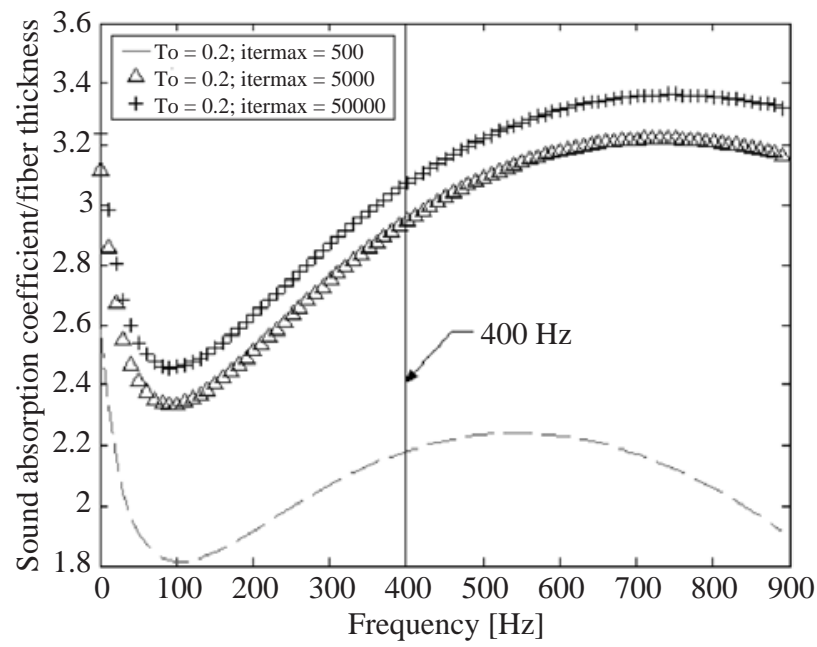

Fig. 11. Objective function of $\alpha /\left(D f_{1}+D f_{2}\right)$ with respect to frequency for various iterations [constraint condition: $D f_{1}+D f_{2}=0.1(\mathrm{~m})$; $\mathrm{m} 1=\mathrm{m} 2=2\left(\mathrm{~kg} / \mathrm{m}^{2}\right) ; q_{1}=q_{2}=0.0006(\mathrm{~m}) ; R_{a}=6300 \mathrm{rayl} / \mathrm{m} ;$ $\left.R_{\mathrm{b}}=40000 \mathrm{rayl} / \mathrm{m}\right]$.

Table 2. Comparison of results for the various iteration numbers

\begin{tabular}{|c|c|c|c|c|c|c|c|c|c|c|c|c|c|}
\hline \multicolumn{3}{|c|}{$\begin{array}{l}\text { SA Control } \\
\text { parameters }\end{array}$} & \multicolumn{10}{|c|}{ Results } & \multirow{2}{*}{$\begin{array}{c}\begin{array}{c}\text { Elapse } \\
\text { time }\end{array} \\
\mathrm{t}(\mathrm{min})\end{array}$} \\
\hline iter $_{\max }$ & $k k$ & $p_{1} \%$ & $d_{1}(\mathrm{~m})$ & $\begin{array}{l}D f_{1} \\
(\mathrm{~m})\end{array}$ & $L_{1}(\mathrm{~m})$ & $p_{2} \%$ & $d_{2}(\mathrm{~m})$ & $\begin{array}{l}D f_{2} \\
(\mathrm{~m}) \\
\end{array}$ & $L_{2}(\mathrm{~m})$ & $\begin{array}{c}\alpha / \\
\left(D f_{1}+D f_{2}\right) \\
\end{array}$ & $\alpha$ & $D f_{1}+D f_{2}$ & \\
\hline 500 & 0.93 & 41.7 & 0.012 & 0.077 & 0.088 & 37.2 & 0.003 & 0.023 & 0.064 & 2.18 & 0.2180 & 0.1 & 0.02 \\
\hline 5000 & 0.93 & 32.8 & 0.005 & 0.079 & 0.054 & 46.5 & 0.003 & 0.021 & 0.060 & 2.94 & 0.2944 & 0.1 & 0.21 \\
\hline$\underline{50000}$ & 0.93 & 38.1 & 0.005 & 0.079 & 0.014 & 48.5 & 0.003 & 0.021 & 0.053 & 3.06 & 0.3069 & 0.1 & 0.22 \\
\hline
\end{tabular}

Note: $D f_{1}+D f_{2}=0.1(\mathrm{~m}) ; \mathrm{m} 1=\mathrm{m} 2=2\left(\mathrm{~kg} / \mathrm{m}^{2}\right) ; q_{1}=q_{2}=0.0006(\mathrm{~m}) ; R_{a}=6300 \mathrm{rayl} / \mathrm{m} ; R_{b}=40000 \mathrm{rayl} / \mathrm{m}$. 
Table 3. Optimal design parameters of sound absorber

\begin{tabular}{|c|c|c|c|c|c|c|c|c|c|c|c|c|}
\hline \multicolumn{13}{|c|}{ Optimal design parameters and result } \\
\hline$p_{1} \%$ & $d_{1}(\mathrm{~m})$ & $\begin{array}{l}D f_{1} \\
(\mathrm{~m})\end{array}$ & $L_{1}(\mathrm{~m})$ & $\begin{array}{c}R_{a} \\
(\mathrm{rayl} / \mathrm{m})\end{array}$ & $p_{2} \%$ & $d_{2}(\mathrm{~m})$ & $\begin{array}{l}D f_{2} \\
(\mathrm{~m})\end{array}$ & $L_{2}(\mathrm{~m})$ & $\begin{array}{c}R_{b} \\
(\mathrm{rayl} / \mathrm{m})\end{array}$ & $\alpha /\left(D f_{1}+D f_{2}\right)$ & $\alpha$ & $D f_{1}+D f_{2}$ \\
\hline 21.0 & 0.014 & 0.042 & 0.060 & 29340 & 49.5 & 0.004 & 0.058 & 0.047 & 3014 & 8.47 & 0.847 & 0.1 \\
\hline
\end{tabular}

Note: $D f_{1}+D f_{2}=0.1(\mathrm{~m}) ; \mathrm{m} 1=\mathrm{m} 2=2\left(\mathrm{~kg} / \mathrm{m}^{2}\right) ; q_{1}=q_{2}=0.0006(\mathrm{~m}) ; k k=0.93 ;$ iter $_{\max }=50000$.

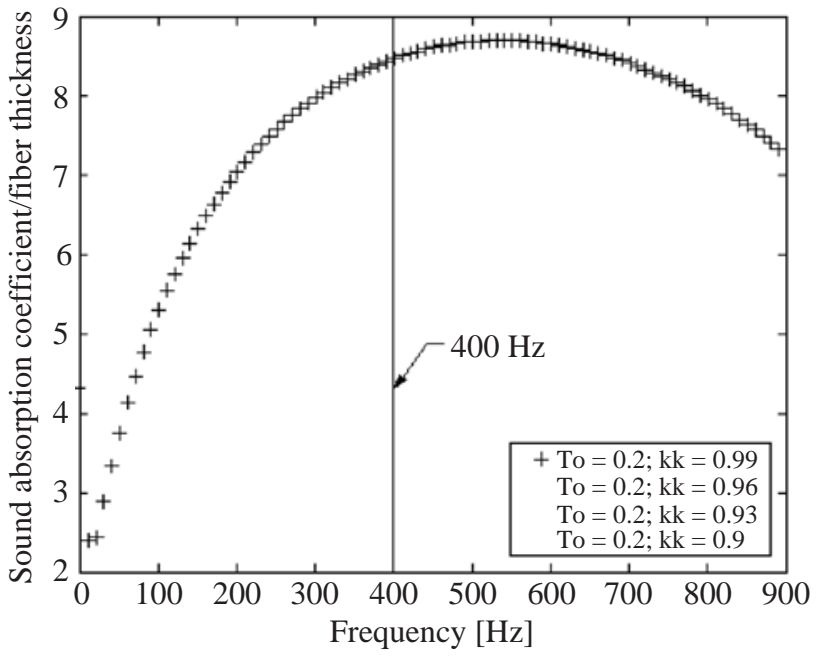

Fig. 12. Objective function of $\alpha /\left(D f_{1}+D f_{2}\right)$ with respect to frequency for various iterations [constraint condition: $D f_{1}+D f_{2}=0.1(\mathrm{~m})$; $\left.\mathrm{m} 1=\mathrm{m} 2=2\left(\mathrm{~kg} / \mathrm{m}^{2}\right) ; q_{1}=q_{2}=0.0006(\mathrm{~m})\right]$

comes efficient and easier to be used. Both the cooling rate $(k k)$ and the iteration number $\left(\right.$ iter $\left._{\max }\right)$ play essential roles in SA optimization. By increasing the iteration in SA, the acoustic performance of $\alpha /$ Do can be improved. Results in Table 2 and Figure 10 reveal that the best objective function of 3.06 is searched. Its related sound absorption coefficient at $400 \mathrm{~Hz}$ is 0.3069 . A further study in Figure 12 indicated that the better objective function will be achieved at the less constraint conditions such as the unlimited flow resistivity of $R_{a}$ and $R_{b}$.

This study definitely offers a simple advance to not only organize the best drawing in sound absorbers but also compromise the minimal thickness and good acoustic performance of absorbers for the space-constrained task, which is occasionally occurred in the enclosed manufacturing system.

\section{REFERENCES}

1. Bies, D.A. and Hansen, C.H., Engineering Noise Control, Unwin Hyman, UK (1988).

2. Cave, A., Nahavandi, S., and Kouzani, A., "Simulation
Optimization for Process Scheduling Through Simulated Annealing," Proceedings of the 2002 Winter Simulation Conference, pp. 1909-1913 (2002).

3. Chang, Y.C., Yeh, L.J., Chiu, M.C., and Lai, G.J., "Shape Optimization on Constrained Single-Layer Sound Absorber by Using GA Method and Mathematical Gradient Methods," Journal of Sound and Vibration, Vol. 286/4-5, pp. 941-961 (2005).

4. Chiu, M.C., "Compact Acoustic Board for Low Frequencies: Experimental Study and Theoretical Analysis," Proceedings of the $18^{\text {th }}$ National Conference on Mechanical Engineering, CSME, C3, pp. 719-724 (2001).

5. Delany, M.E. and Bazley, E.N., "Acoustical Properties of Fibrous Absorbent Materials," Applied Acoustics, Vol. 13, pp. 105-116 (1969).

6. Ingard, K.U. and Bolt, R.H., "Absorption Characteristics of Acoustic Material with Perforated Facings," Journal of the Acoustical Society of America, Vol. 23, pp. 533-540 (1951).

7. Kirkpatrick, S., Gelatt, C.D., Jr. and Vecchi, M.P., "Optimization by Simulated Annealing," Science, Vol. 220, No. 4598, pp. 671-680 (1983).

8. Lee, F.C. and Chen, W.H., "Acoustic Transmission Analysis of Multi-Layer Absorbers," Journal of Sound and Vibration, Vol. 248, pp. 621-634 (2001).

9. Metropolis, A., Rosenbluth, W., Rosenbluth, M.N., Teller, H., and Teller, E., "Equation of Static Calculations by Fast Computing Machines," The Journal of Chemical Physics, Vol. 21, No. 6, pp. 1087-1092 (1953).

10. Nolle, L., Armstrong, D.A., Hopgood, A.A., and Ware, J.A., "Simulated Annealing and Genetic Algorithms Applied to Finishing Mill Optimization for Hot Rolling of Wide Steel Strip," International of Knowledge-Based Intelligent Engineering System, Vol. 6, No. 2, pp. 104111 (2002).

11. Timar, P.L., Noise and Vibration of Electrical Machines, Elsevier Science, New York (1989).

12. Wang, C.N. and Torng, J.H., "Experimental Study of the Absorption Characteristics of Some Porous Fibrous Materials," Applied Acoustics., Vol. 62, pp. 447-459 (2001). 